\title{
Listeria cross contamination levels in raw ice cream mix can serve as a predictor of their potential presence as heat-injured cells
}

\author{
Neha Neha, ${ }^{*}$ Sanjeev Anand, ${ }^{* 1}$ Gemechis Djira, $†$ Brian Kraus, $\ddagger$ and Suresh Sutariyał \\ *Midwest Dairy Foods Research Center, Dairy and Food Science Department, and \\ †Department of Mathematics and Statistics, South Dakota State University, Brookings 57007 \\ ¥Wells Enterprises Inc., Le Mars, IA 51031
}

\section{ABSTRACT}

Listeriosis is a life-threatening infection caused by foods contaminated with Listeria monocytogenes. Some of the major ice cream recalls in recent years reaffirm the ability of this food-borne pathogen to survive in diverse dairy processing environments and cause cross contamination. Inspection reports revealed certain lapses in implementing adequate hygienic practices for Listeria persistence in the processing environment, leading to cross contamination of ice cream. The higher levels of cross contamination of raw ice cream mix might result in random heat-injured cells when exposed to minimum heat treatment $\left(69^{\circ} \mathrm{C}\right.$ for $\left.30 \mathrm{~min}\right)$. These heat-injured cells could later recover under abusive storage and handling conditions and pose a health risk. Evidence about the presence of injured cells in ice cream mix may thus prove useful to establish the overall Listeria risk, which was the aim of this study. Challenge studies were conducted to evaluate the dosedependent presence of heat-injured cells of Listeria. Ice cream mix formulations of 4 different types $(36,40,42$, and $45 \%$ total solids) were inoculated at 2.0, 3.0, and $4.0 \mathrm{log} \mathrm{cfu} / \mathrm{g}$ levels of Listeria innocua (an established surrogate). The dose levels were selected based on a likely cross contamination on the raw side from environmental Listeria, especially due to their resident nature and growth in harborage sites. The samples were exposed to minimum heat treatment $\left(69^{\circ} \mathrm{C}\right.$ for $\left.30 \mathrm{~min}\right)$ and the survivors, including heat-injured cells, were enumerated using standard protocols. A binary logistic regression model was fitted for evaluating the severity of risk. The influence of total solids, water activity, and $\mathrm{pH}$ variability were also studied on Listeria survival. The enrichment protocol, using buffered Listeria enrichment broth, followed by plating on modified oxford

Received January 23, 2018.

Accepted July 10, 2018.

${ }^{1}$ Corresponding author: Sanjeev.anand@sdstate.edu agar and Rapid L'mono medium, revealed the random presence of heat-injured cells in buffered Listeria enrichment broth, only at the highest dose level of $4+$ logs. Any potential risk from heat-injured cells was thus limited only to the highest levels of cross contamination, irrespective of the type of the mix. Significantly, none of the pasteurized ice cream mix samples supported the recovery of any heat-injured cells of Listeria during 72 $\mathrm{h}$ holding at $7^{\circ} \mathrm{C}$, even at the highest dose level of $4+$ logs, under the conditions of experimentation. The level of cross contamination (dose) emerged as a predictor of the potential presence of heat-injured cells of Listeria exposed to minimum pasteurization treatment.

Key words: injured cells, ice cream, recovery, risk analysis, Listeria

\section{INTRODUCTION}

Listeria monocytogenes is 1 of the 5 most implicated food-borne pathogens, known for its ubiquity, ability to withstand freezing temperatures, and persistence in food processing facilities. The psychrotrophic grampositive pathogen grows between -0.4 and $50^{\circ} \mathrm{C}$, with optimum growth between 30 and $37^{\circ} \mathrm{C}$, and at a neutral $\mathrm{pH}$. It, however, can also grow well at a much lower $\mathrm{pH}$ range of 5.0 to 5.7 at $4^{\circ} \mathrm{C}$ and 4.3 to 5.2 at $30^{\circ} \mathrm{C}$ (Farber and Peterkin, 1991). Listeria has become a greater challenge for the food industry, as it can withstand different types of processing stresses and can survive in a moist environment, conditions that commonly exist in dairy processing plants. The Food Advisory Committee of the Food and Drug Administration (FDA) has even established a zero-tolerance policy for Listeria in ready-to-eat products, such as meat and poultry products maintained by Food Safety and Inspection Service (FSIS, 2014).

In the context of raw milk contamination, the prevalence of $L$. monocytogenes on cattle and small ruminant farms was reported to be 22.2 and $16.8 \%$, respectively, in New York and adjacent states (Nightingale et al., 2004). Feeding cattle with poor-quality silage, a lack 
of following good practices during milking, and insufficient cleaning of cows enhanced the possibility of raw milk contamination with L. monocytogenes (Sanaa et al., 1993; Hunt et al., 2012). On the other hand, sometimes mastitis, encephalitis and abortions due to Listeria infection in cattle can also result in shedding of organisms in the milk (Fleming et al., 1985), which in turn leads to cross contamination of milk by Listeria. The intracellular presence of some Listeria spp. within leukocytes might result in their greater ability to survive minimum pasteurization temperatures (Doyle et al., 1987). For instance, in Massachusetts, an inadequate filtering system in a plant failed to clarify the milk before pasteurization and introduced leukocytes into the system. This resulted in an inadequate pasteurization effect and, hence, led to an outbreak due to presence of intracellular lipid-shielded organisms (Bearns and Girard, 1958). With regard to ice cream, according to Centers for Disease Control, 9 Listeriarelated ice cream recalls occurred during 2014 and 2015. The Blue Bell incidence in March 2015 led to 10 hospitalizations and 3 deaths (CDC, 2015). Later in April 2015, Jeni's Splendid Ice Cream tested positive for Listeria, forcing a recall of all their products (FDA, 2016). During sampling of 2 dairy processing plants to evaluate the traditional and molecular methods for Listeria detection, it was observed that the molecular method depicted higher Listeria contamination within the processing environment. Some equipment within the dairy processing environment have previously been shown to be contaminated with $L$. monocytogenes to a level of $10^{4}$ to $10^{5}$ cfu (Alessandria et al., 2010). In another recent recall involving Fieldbrook Foods ice cream bars, although no illnesses were confirmed, the finished sample tested positive for L. monocytogenes (FDA, 2018).

In the context of ice cream safety, pasteurization of ice cream mix is regarded as the terminal kill step. However, several studies demonstrated that L. monocytogenes could survive a minimum HTST process under certain conditions, such as if relatively large numbers were present in milk, if growth at elevated temperatures had occurred, if the level of background microflora reached a certain level, and whether certain ice cream constituents were present (Fleming et al., 1985; Doyle et al., 1987; Fernandez Garayzabal et al., 1987; Bunning et al., 1988; Knabel et al., 1990; Farber et al., 1992; Holsinger et al., 1992). In the study conducted by Doyle et al. (1987), L. monocytogenes was isolated from milk in 6 of 9 trials in which the heat treatment was $71.7^{\circ}$ to $73.9^{\circ} \mathrm{C}$ for $16.4 \mathrm{~s}$ with the Listeria population up to $4.8 \times 10^{4}$ cells $/ \mathrm{mL}$ of milk. Similarly, a study conducted by Farber et al. (1988) also revealed the significance of large inoculum size and potential survival abilities of the organisms during pasteurization. In addition to the inoculum size, the physiological state of the cells and their heterogeneous response to stress also influence the survival of Listeria (Pascual et al., 2001). Holsinger et al. (1992) reported that, although the guidelines for pasteurization time-temperature of ice cream mix adequately inactivated L. monocytogenes, it is important to take every precaution to inactivate the organism, as some major ingredients of ice cream, such as stabilizers, are associated with the increased thermal tolerance, possibly through entrapment of the organism in the 3-dimensional network formed with casein micelle, as reported by Glicksman (1983). While concluding the adequacy of pasteurization, Lou and Yousef (1999) also reported on the general use of pasteurization temperatures well above the minimum legal limit being practiced by many raw milk processors. Additionally, Besse (2002), in a review, mentioned that it was not feasible to eliminate all bacteria with thermal treatment, as heating led to a physiological stress within cells, leaving them injured. These injured cells could repair themselves once the favorable conditions return and provide a threat to the product quality (McMahon et al., 2000). It is also important to mention that in most of these studies, either a general-purpose enumeration medium was used or it was not clear if any selective enrichment protocol was adopted. Many previous studies have shown that enrichment process greatly influences the recovery of true numbers of Listeria (Lund et al., 1991; Warburton et al., 1991; Flanders et al., 1994). Detection of any stressed and injured cells becomes further complicated due to diverse background microflora, and most of the general enumeration protocols may not prove to be as effective (Vlaemynck and Moermans, 1996; Pritchard and Donnelly, 1999).

It would thus be useful to evaluate any potential presence of heat-injured cells in ice cream mix exposed to minimum pasteurization treatment by specifically employing the standard enrichment protocol (FDA, 2017), and not by simply relying on direct plating on general-purpose media. This approach can also help restrict the overgrowth of background microflora including Bacillus spp., which has been reported to inhibit the recovery and growth of heat-injured L. monocytogenes (Buchanan, 1990; Tharrington and Sorrells, 1992). Although, such heat-injured cells have so far not been reported to be the cause of any outbreaks, studying their presence can help us design more robust risk assessment protocols. In view of this, we aimed to study the possibility of detecting heat-injured cells of Listeria in ice cream mix contaminated with large inocula (up to $4+\operatorname{logs}$ per gram of mix), subjected to minimum heat treatment of $69^{\circ} \mathrm{C}$ for $30 \mathrm{~min}$, and enumerated by employing the FDA-approved enrichment protocol 
(FDA, 2017). We also evaluated the chance of Listeria recovery during later stages of handling and processing of pasteurized mix in this study. Binary distribution models were developed by applying logistic regression, where the interactive effect of dose, ice cream mix storage temperature and storage duration, water activity, and $\mathrm{pH}$ was also evaluated on the presence and potential recovery of heat-injured cells.

\section{MATERIALS AND METHODS}

\section{Types of Ice Cream Mixes and Basic Analysis}

Source of Raw Ice Cream Mixes. Raw ice cream mix formulations of $36,40,42$, and $45 \%$ TS levels were obtained in 3.78-L packs, in temperature-controlled containers, from a commercial ice cream manufacturer. The average fat content in these formulations were 7.2, $14.2,16.3$, and $16.4 \%$, respectively. The average sugar content varied from 19.3 to $22.2 \%$, whereas protein content varied from 3.1 to $4.2 \%$. The $45 \%$ TS mix samples contained 3\% chocolate powder. These were analyzed, upon receiving, for background bacterial counts and chemical parameters such as water activity and $\mathrm{pH}$. A 90-g portion of each ice cream mix sample was set aside for conducting the Listeria challenge studies as detailed below. Three trials, each in replicates of 3 , were conducted for each TS level.

Microbiological Analysis of Ice Cream Mixes. To establish the background microflora, ice cream mix samples were plated on Brain Heart Infusion (BHI) agar (Oxoid, Thermo Fisher Scientific, Watham, MA) for aerobic plate counts by following standard methods (Wehr and Frank, 2004). Eleven grams of the respective sample was aseptically drawn and mixed with $99.0 \mathrm{~mL}$ of PBS using a stomacher (Stomacher 400 Circulator, Seward Laboratory System Inc., Bohemia, NY) for 30 $\mathrm{s}$ to obtain the first dilution. Further serial dilutions were made, as necessary, in PBS and plated on BHI agar. The plates were incubated at $37^{\circ} \mathrm{C}$ and colonies were counted at 24 to $48 \mathrm{~h}$ for obtaining aerobic plate counts.

Chemical Analysis of Ice Cream Mix Samples. The ice cream mix samples were tempered to ambient temperature. The water activity of the samples was measured using Aqua Lab CX-2 system (Aqua Lab, Decagon Devices Inc., Pullman, WA), and the $\mathrm{pH}$ was measured using A321 pH meter (Orion Star A321, Thermo Fisher Scientific).

\section{Challenge Studies Using Listeria innocua}

Sourcing L. innocua and Culture Propagation. Pure culture of L. innocua ATCC 33090, an established surrogate of L. monocytogenes (Friedly et al., 2008; Liu et al., 2009), was procured from American Type Culture Collection (Manassas, VA). It was activated in BHI broth (Oxoid, Thermo Fisher Scientific) by incubating at $37^{\circ} \mathrm{C}$ for $24 \mathrm{~h}$. To achieve the midexponential cells, the activated culture was subcultured in $9 \mathrm{~mL}$ of BHI broth, and the 6-h growth was pelleted out and suspended in PBS to get the desired numbers of cells for inoculation purposes. For long-term storage, the pelleted culture was maintained in $1.8-\mathrm{mL}$ cryogenic vials (Copan Diagnostic Inc., Murrieta, CA) that contained sterile beads and glycerol. The vials were stored in a NuAire ultralow deep freezer (NuAire Inc., Plymouth, $\mathrm{MN})$ at $-80^{\circ} \mathrm{C}$ until further use.

Inoculation and Pasteurization of Ice Cream Mix Samples. To study the dose response, ice cream mix samples were tempered to $40^{\circ} \mathrm{C}$ in a water bath (Wehr and Frank, 2004) and inoculated at the average dose levels of $\log 2.0,3.0$, and $4.0 \mathrm{cfu} / \mathrm{g}$ of $L$. innocua activated culture, as explained above. The 6 -h grown culture was centrifuged $\left(2,000 \times g\right.$ for $15 \mathrm{~min}$ at $\left.4^{\circ} \mathrm{C}\right)$ and washed twice with PBS to harvest the cells. Appropriate cell suspensions $(2+, 3+$, and $4+\operatorname{logs} \mathrm{cfu} / \mathrm{g})$ were made by diluting the harvested culture in PBS. The inoculation levels of raw ice cream mix samples were selected to simulate any potential environmental cross-contamination situation, as discussed in the introduction. The inoculated ice cream mix samples were minimally batch pasteurized at $69^{\circ} \mathrm{C}$ for $30 \mathrm{~min}$ (corresponds to $80^{\circ} \mathrm{C}$ for $25 \mathrm{~s}$; FDA, 2015) in a shaker water bath (Lab companion AAH44063U 17L reciprocal shaking water bath, Cole-Parmer, Vernon Hills, IL). During heating, the core temperature was continuously monitored using the temperature probe. The samples were then rapidly cooled in an ice bath before further analysis. Each experimental trial was done in replicates of 3 and repeated 3 times. The experiments were also repeated under the production environment by using HTST conditions to evaluate under production conditions.

Recovery of Survivors Using Direct Plating Method. For each direct analysis, $25 \mathrm{~g}$ of inoculated and pasteurized ice cream mix sample was drawn and suspended in $225 \mathrm{~mL}$ of PBS, followed by further serial dilutions as necessary. Appropriate dilutions were direct plated on an esculin-based medium, Modified Oxford Agar (MOX; Remel, San Diego, CA) to enumerate the Listeria cells that might have survived the heat treatment. The direct plating on Oxford agar likely supports the growth of uninjured populations (Hansen and Knøchel, 2001). The plates were incubated at $37^{\circ} \mathrm{C}$ for $24 \mathrm{~h}$. The incubated plates were observed for typical Listeria colonies, which were small black colonies with a black halo (Park et al., 2014). 
Recovery of Heat-Injured Cells Using the BAM Enrichment Protocol. Additionally, to enumerate any heat-injured cells of Listeria, an enrichment protocol was used as recommended by FDA (Bacteriological Analytical Manual, FDA, 2017). A 25-g portion each of the laboratory-pasteurized inoculated samples was suspended in $225 \mathrm{~mL}$ of buffered Listeria enrichment broth (BLEB) and incubated for $4 \mathrm{~h}$ at $30^{\circ} \mathrm{C}$. Listeria selective enrichment supplements (acriflavine $\mathrm{HCl}$, nalidixic acid, and cycloheximide) were added after $4 \mathrm{~h}$ and the samples were further incubated at $30^{\circ} \mathrm{C}$. At intervals of 24 to $48 \mathrm{~h}$, BLEB enrichments were streaked on MOX agar and a chromogenic selective medium (Rapid L'mono, Bio-Rad Laboratories Inc., Hercules, CA; RLM) to show the recovery of heat-injured cells. The typical Listeria colonies on MOX appeared black with black zones, whereas on RLM the colonies were white, with or without halo. The results were recorded as positive or negative, based on the presence or absence of colonies on the selective media used for streaking, due to the recovery of heat-injured cells of Listeria.

Recovery of Heat-Injured Cells in Ice Cream Mixes. The inoculated and pasteurized ice cream mix samples were stored up to $72 \mathrm{~h}$ at $7^{\circ} \mathrm{C}$ (to simulate the common duration of ice cream mix storage in the ice cream industry) to observe the recovery of any heatinjured cells in the ice cream mix itself. To study this, the representative ice cream mix samples from each TS level, in individual treatment bottles, were held at $7^{\circ} \mathrm{C}$ (Isotemp low temperature incubator, MDL 146E, Thermo Fisher Scientific) on a shaker. The samples drawn at the end of $72 \mathrm{~h}$ were serially diluted using PBS, followed by direct plating on MOX and RLM agar to enumerate any heat-injured Listeria cells that might have been recovered during the mix storage process in the ice cream mix samples.

MALDI-TOF-Based Identification of Isolates and Microscopy of Uninjured and Injured Cells. Selected isolates were streaked on RLM and MOX agar plates, and the pure colonies thus obtained were used for the confirmatory identification using MALDI-TOF (Thouvenot et al., 2018; analysis conducted at the Diagnostic Lab, Veterinary and Biomedical Sciences Department, South Dakota State University). In addition, the intact and injured Listeria cells were also observed under a scanning electron microscope (Hitachi S-3400N, Hitachi America Ltd., Tarrytown, NY), located in the Daktronics Engineering Hall, South Dakota State University. To study the morphological changes in heat injured Listeria, the bacterial suspensions in BHI broth were exposed to minimal thermal treatment and the pre- and post-pasteurization suspensions were placed on the glass slides. These were air-dried follow- ing the air-drying method described by Hassan et al., (2010), with slight modifications. For scanning electron microscopy, the air-dried samples were sputter coated with a $10-\mathrm{nm}$ thick layer of deposition of $99 \%$ gold and observed at $10 \mathrm{kV}$ accelerating voltage by maintaining a distance of $10 \mathrm{~mm}$ from the slide.

\section{Data Analysis and Developing Risk Assessment Models}

Descriptive Analysis. Graphical descriptive analyses were performed to study the marginal and joint distributions of water activity and $\mathrm{pH}$ by TS levels. Furthermore, we constructed a scatterplot of $\mathrm{pH}$ by water activity (grouped by TS levels) to uncover if any pattern was present.

ANOVA Model to Compare Several Groups. The results related to plate counts were subjected to ANOVA using SAS 6.12 (SAS Institute Cary, Cary, NC). The level of significance was set to $5 \%$.

Binary Logistic Regression Analysis. For the challenge studies, 3 dose levels ( $\log 2.0,3.0$, and 4.0) were tested for thermal resistance and presence of any heat-injured cells of Listeria. Ice cream mix samples with different levels of TS $(36,40,42$, and $45 \%)$ were inoculated, pasteurized at $69^{\circ} \mathrm{C}$ for $30 \mathrm{~min}$, and direct plated on MOX agar for the presence or absence of survivors. To model the risk, the standard binary logistic regression was applied by using R-3.3.2 (The R Foundation, Vienna, Austria). The binary dependent variable included the absence of heat-injured cells, recorded as 0 (zero), and their presence (recovery), recorded as 1 (one).

During further study using enrichment broth, the independent variables considered for the potential recovery of heat-injured cells were dose, temperature, water activity, and $\mathrm{pH}$. At a later stage of the modeling process, penalized logistic regression was also used due to the quasi-complete separation. Nonsignificant predictor variables were eliminated and the water activity and $\mathrm{pH}$ data were used to study their interaction with different TS levels to create a baseline.

\section{RESULTS AND DISCUSSION}

\section{Influence of Ice Cream Types on Microbiological Quality and Chemical Parameters of Ice Cream Mix Samples}

Raw ice cream mixes of different types and TS levels (36, 40, 42, and 45\%) were evaluated for the initial bacterial loads and some chemical parameters. The average aerobic plate counts of raw ice cream mix samples varied 
within a narrow range from 4.65 to $5.67 \log _{10} \mathrm{cfu} / \mathrm{g}$. Our data related to aerobic counts in samples were observed to be consistent for all the 3 trials, conducted in the replicates of 3 , for each formulation. This data helped us to establish a base value for the background bacterial load in raw ice cream mix samples tested. Such background counts in raw ice cream mix samples may result due to carryover contamination from different ice cream mix ingredients and the environmental cross contamination on the raw side of processing. Although we did not come across any other such reports on raw ice cream mix bacterial counts, even processed ice cream has been shown to have range from 2 to 5 logs (Campbell, 2015). The raw ice cream mix, along with its natural background microflora, was chosen for inoculation studies to simulate commercial manufacturing conditions. The experiments were designed to potentially evaluate the effect of background microflora, if any, on the survival of heat-injured cells when exposed to minimum pasteurization. This information would also be useful in future studies to evaluate their influence on the potential recovery of any heat-injured cells during later holding of ice cream mix under extended storage before further processing. The cross contamination of raw ice cream mix with Listeria, and the later presence of heat-injured cells, may also be influenced by the level of background microflora in the raw ice cream mix. With regard to the possibilities of Listeria contamination in raw ice cream mix, carryover of the pathogen in raw milk and potential cross contamination in the processing facility were hypothesized. In a previous study, about $18.8 \%$ of the equipment sites, $54.7 \%$ of the environmental sites, and $44.4 \%$ of the raw milk samples had Listeria in Northern Ireland (Fox et al., 2009). Similarly, O'Donnell (1995) indicated that $15.43 \%$ of raw milk samples from bulk tanks in England and Wales were contaminated with Listeria spp. That study also reported a significant increase in Listeria population during a specific time of the year, when the cows were housed for that particular period. In addition, some of the previous reports depicted the presence of Listeria in the dairy processing environment, more prominently the wet drains and floors and walls. It was thus inferred that Listeria contamination is more likely to occur on the raw side within an ice cream processing environment. Hence, to simulate the actual commercial conditions that might lead to Listeria cross contamination, raw ice cream mix samples were used along with background microflora for our study. This approach also takes in to account any influence of background microflora, which might compete with Listeria contaminants within the ice cream mix matrix itself.

Chemical analysis of raw ice cream mix samples revealed that the water activity $\left(\mathbf{a}_{\mathbf{W}}\right)$ varied within a narrow range from 0.97 to 0.98 and $\mathrm{pH}$ from 6.4 to 6.7, as also reported by Gougouli et al. (2008). This helped us to establish that the ice cream mix samples selected for experimentation were within normal range of variations. The information on $\mathrm{pH}$ and $\mathrm{a}_{\mathrm{W}}$ proved useful when evaluating the interaction of these 2 variables as covariates for developing regression models for the survival of heat-injured cells of Listeria due to the cross-contaminated ice cream mixes. The $\mathrm{pH}$ and $\mathrm{a}_{\mathrm{W}}$ values were found in the typical range, as generally encountered in commercial manufacturing, and showed the least variability. The discussion in the following sections further elaborates the interaction of these variables and their influence on any survival potential of heat-injured cells of Listeria.

\section{Typical Colony Morphology of Listeria and Predominant Background Microflora}

The Listeria-selective media, MOX and RLM agar, proved very useful in isolating and differentiating $L$. innocua from the background microflora, which primarily included Microbacterium and thermoduric endosporeformers of Bacillus species. Figure 1 reveals that typical colonies of $L$. innocua (the inoculated organism) were round, approximately $1.0 \mathrm{~mm}$ in diameter, black, and surrounded by a black zone (Remel Manuals \& Protocols, https://www.thermofisher.com/order/catalog/ product/R01613), and white, with or without halo on RLM (Bio-Rad specification sheet; http://www.bio-rad .com/webroot/web/pdf/lsr/literature/Bulletin_3046B .pdf). However, the typical colony morphology of the background species Microbacterium was black with a black zone, approximately $4 \mathrm{~mm}$ in diameter, and was elevated on MOX, whereas the colonies were transparent and round on RLM agar medium (the color of the medium turned pink; Figure 2A and B). Figure 3 depicts typical colony morphology of Bacillus, which appeared as scattered colonies with cottony appearance on MOX. Further confirmation of selected colonies was done using MALDI-TOF. This additional information can prove useful for further studies and prevent any false positive identification in the presence of background microflora.

To study any morphological changes in the heatinjured cells of Listeria, intact and injured Listeria cells were observed by Gram-stained smears as well as scanning electron microscope. In Figures $4 \mathrm{~A}$ and B, the heat-injured cells appeared to be shorter rods clumped together with ruffled surfaces compared with the intact (uninjured cells, preheat treatment). This observation was similar to a previous report, where the ultrastructure analysis of heat-injured cells indicated cytoplasmic clearance and swollen cell surfaces as an effect of heat 
A

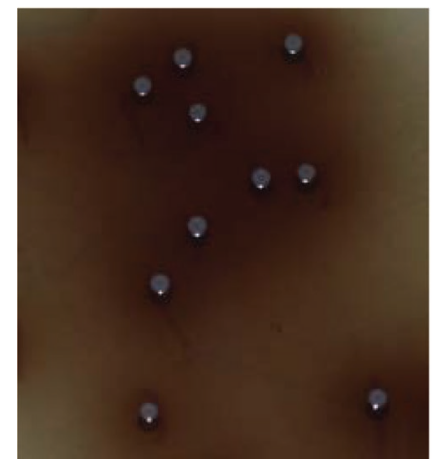

B

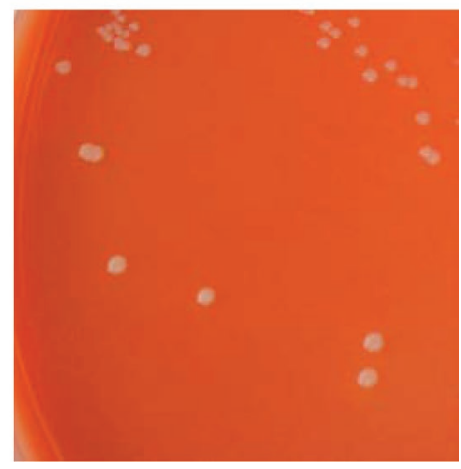

Figure 1. Typical colonies of Listeria innocua (the inoculated organism) appeared to be round, approximately $1.0 \mathrm{~mm}$ in diameter, black in color, and surrounded by a black zone on Modified Oxford agar (MOX; Remel, San Diego, CA) medium (A) and round, white, and with or without halo on Rapid L'mono (RLM; Bio-Rad Laboratories Inc., Hercules, CA) agar medium (B). Color version available online.

injury, whereas no leakage of cellular components was observed (Novak and Juneja, 2001). Such injured cells might recover on restoration of the adequate growth conditions, such as temperature and composition of the product (Mackey et al., 1994). Based on these important observations, our study emphasized the significance of the presence and recovery potential of heat-injured cells to establish their relationship with the crosscontamination levels (dose levels). This also helped us generate evidence in support of the hypothesis that the presence of Listeria heat-injured cells is dependent on the levels of cross contamination, and such injured cells may serve as a determinant of risk from injured cells in ice cream mix exposed to minimum pasteurization.

A

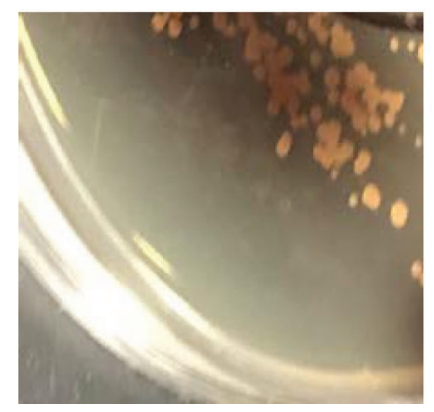

B

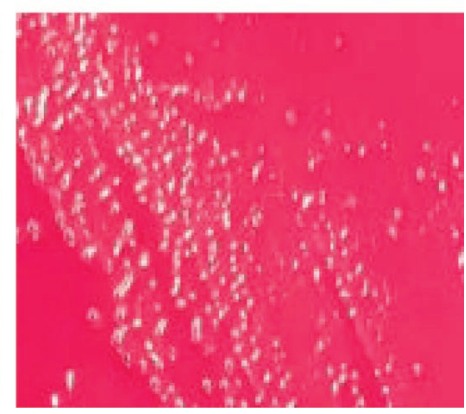

Figure 2. Typical colony morphology of Microbacterium, which appeared black with a black zone, approximately $4 \mathrm{~mm}$ diameter, and elevated on Modified Oxford (Remel, San Diego, CA) agar medium (A). These colonies appeared transparent and round on Rapid L'mono (Bio-Rad Laboratories Inc., Hercules, CA) agar medium (the color of the medium turned pink; B). Color version available online.

\section{Risk Analysis of Listeria-Contaminated Raw Ice Cream Mix}

The microbiological risk analysis models include elements such as hazard characterization and levels, potential exposure, and relative severity of risk (Codex Alimentarius Commission, 1999; EPA, 2012). Keeping the fundamental risk analysis in mind, the overall objective of our study was to evaluate if the cross contamination levels of Listeria in raw ice cream mix (representing any environmental cross contamination under the industrial processing) could influence their later survival as heatinjured cells (as shown by selective enrichment) against minimum pasteurization treatment.

Relationship of Cross Contamination Levels (Dose Response) with Intact (Uninjured) Cells. In the present study, the influence of dose level (representing potential environmental cross contamination situations) was evaluated on any intact cells. Results obtained by direct plating of thermally treated inoculated raw ice cream mix samples did not detect any survivors (uninjured intact cells) at any of the inoculation levels of 2, 3, or $4 \log \mathrm{cfu} / \mathrm{g}$. Such enumeration protocols have previously been reported to be suitable for detecting uninjured populations (Hansen and Knøchel, 2001). These observations also support some of the previous reports, which demonstrated that L. monocytogenes

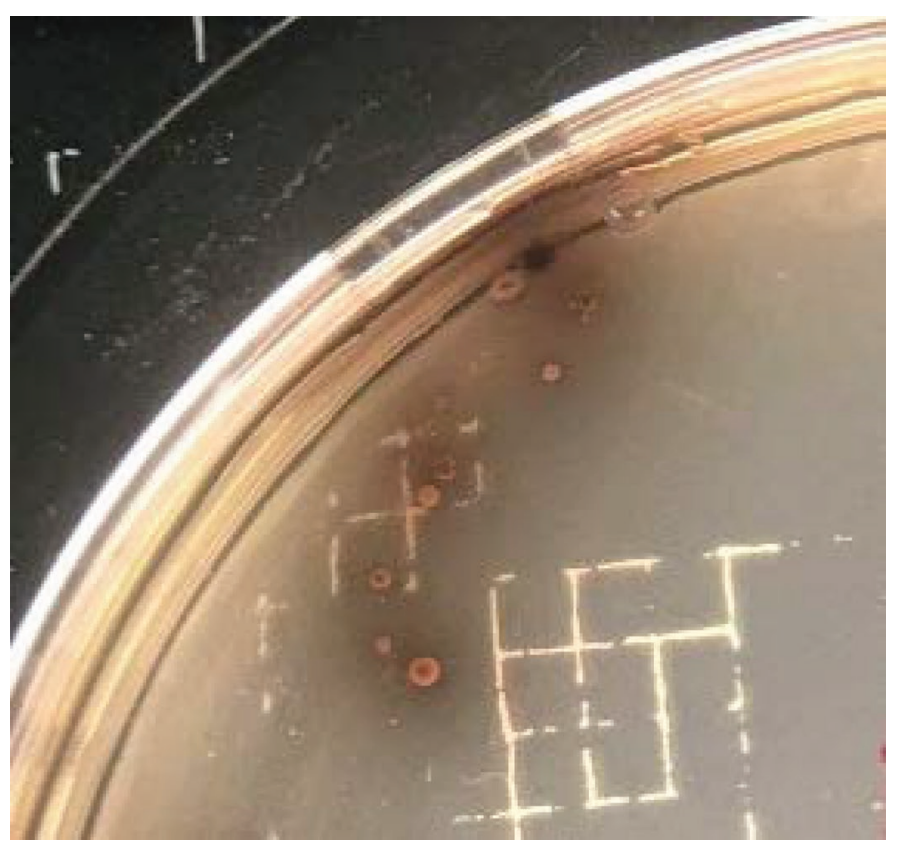

Figure 3. Typical colony morphology of a contaminant, Bacillus sp., which appeared as scattered colonies with cottony appearance on Modified Oxford (Remel, San Diego, CA). Color version available online. 
did not survive a proper pasteurization process in ice cream mix with decimal reduction $\left(\mathrm{D}_{79.4^{\circ} \mathrm{C}}\right)$ value of 0.5 s (Bradshaw et al., 1987; Holsinger et al., 1992).

Relationship of Cross Contamination Levels (Dose Response) with Injured Cells. As the direct plating technique is usually not suitable for the recovery of stressed cells (Jasson et al., 2010), BLEB enrichment protocol is recommended (FDA, 2017) to estimate the presence of injured cells in a product matrix. Following the enrichment protocol, we detected a random presence of some heat-injured cells at the highest dose level of cross contamination (depicted by average $\log 4.0$ inoculation levels) in all 4 types of ice cream mixes when subjected to minimum pasteurization treatment. As reported previously, this could be due to the sublethal damage of cytoplasmic membrane, also known as structural damage (Hauben et al., 1996; Pagán and Mackey, 2000; Ritz et al., 2001), or damage to intracellular components, also known as physiological damage (Niven et al., 1999; Ritz et al., 2002). As the heat-injured cells were only detected at the highest inoculation levels, the average dose level of $\log 4.0$ was considered for risk assessment and to evaluate its role as a predictor of the presence of heat-injured cells when exposed to minimum pasteurization.

As Listeria is a high-risk pathogen, especially for pregnant women and elderly people (Choi et al., 2016), it is important to establish the accurate risk assessment models. Traditionally, a quantitative risk assessment model focuses on preventing, regulating, and understanding the risk due to pathogenic microorganisms

A

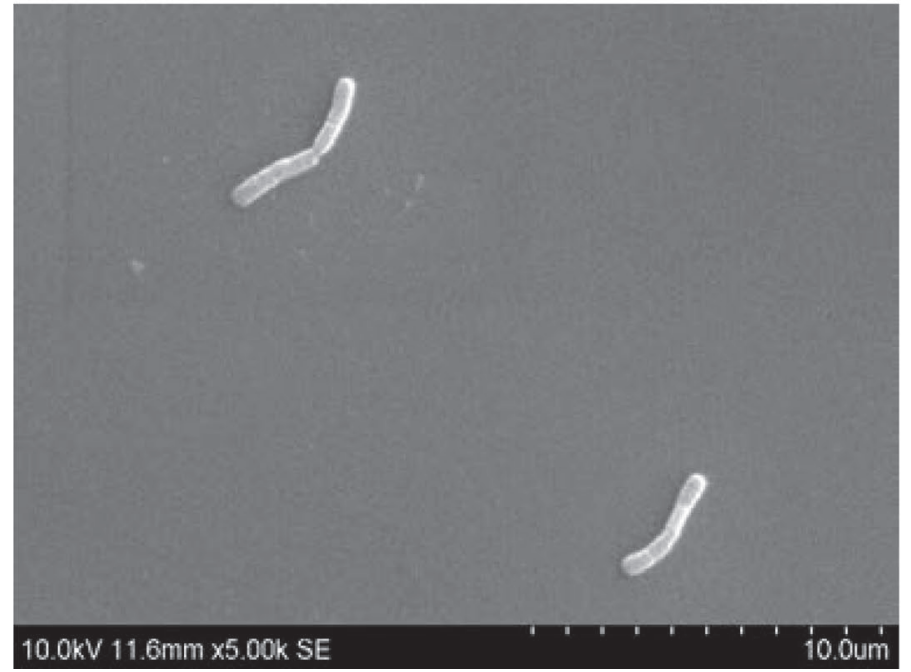

(EPA, 2012). However, such risk assessment models generally do not consider the presence and recovery potential of injured cells, and thus may not adequately address the risk. As per one such study (Roso, 1995) based on Monte Carlo simulations, 99\% of the iterations showed less than 100 cells per serving (as low as 3.7 cells/g of Listeria monocytogenes). Our study thus provided significant information related to injured cells that could prove useful in conducting risk assessment for the process of ice cream mix storage and handling. Such heat-injured cells may have the potential to recover and cause a risk (Bunduki et al., 1995). The dose (depicting the level of potential cross contamination from the processing environment on the raw side) emerged as a predictor of the random presence of heat-injured cells. A previous report by Chen et al. (2016) for creating a probabilistic model and linking it to the bacterial numbers, also depicted the importance of using selective medium to recover low number of uninjured cells of Listeria. Hence, our study puts forth a case for emphasizing the significance of using enrichment protocol to enumerate any random presence of heat-injured cells in developing more robust risk assessment approach.

Recovery of Heat-Injured Cells in Ice Cream Mix. At this point in the study, it became clear that only high level of cross contamination (log 4.0 or higher) could result in postpasteurization detection of some heat-injured cells from the inoculated ice cream mix when subjected to minimum pasteurization. However, the detection of heat-injured cells was only accomplished by using the selective enrichment protocol using

\section{B}

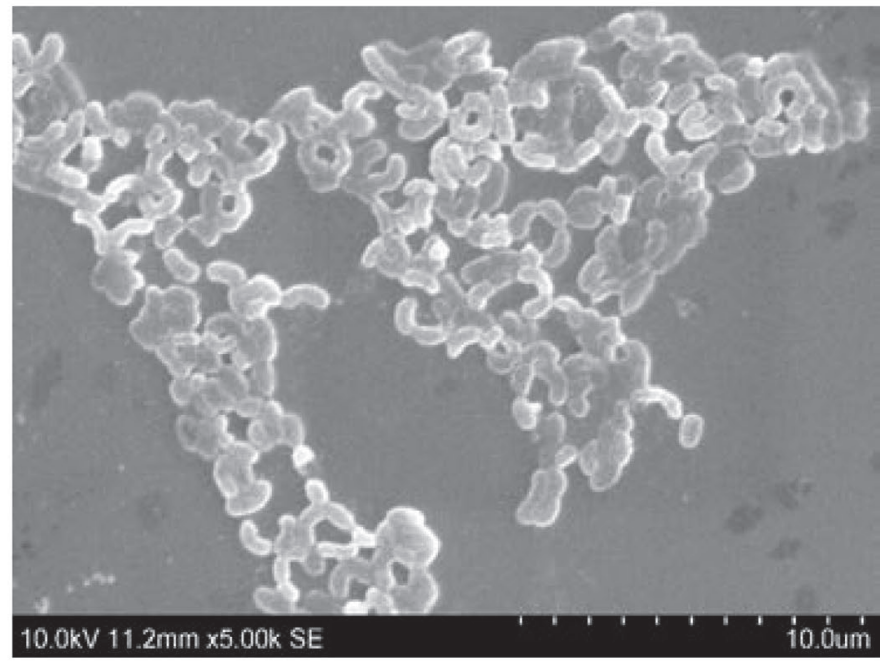

Figure 4. Scanning electron microscopic images of Listeria innocua in Brain Heart Infusion (BHI) agar (Oxoid, Thermo Fisher Scientific, Watham, MA) broth showing intact cells (A), and thermally treated cells (B). Magnification $=10 \mathrm{~K}$. 
BLEB (BAM protocol, FDA, 2017) under the optimal growth conditions of organism. To create a more realistic assessment for the ice cream industry, the recovery potential of heat-injured cells of $L$. innocua was evaluated within ice cream mix itself under the mix aging and storage conditions. The inoculated and pasteurized ice cream mix samples of different types, with TS levels of $36,40,42$, and $45 \%$, were stored at $7^{\circ} \mathrm{C}$ up to a maximum duration of $72 \mathrm{~h}$ (PMO, 2015). Significantly, none of the samples showed recovery of any heat-injured cell in the ice cream matrix itself during the entire process of mix storage under the conditions of experimentation, which affirms the safety of the standard ice cream manufacturing process. However, further studies in this direction are necessary to clearly understand the role of the random presence of heat-injured cells in developing risk analysis to prevent any unintended consequences, especially during mishandling and any abused conditions.
Influence of Covariates on Risk Assessment. The interactions of all the covariates (dose, TS, temperature and duration of mix storage, $\mathrm{a}_{\mathrm{W}}$, and $\mathrm{pH}$ ), and their influence on the recovery of heat-injured cells, were also studied by fitting a binary logistic model. To establish any relationship of $\mathrm{pH}$ and $\mathrm{a}_{\mathrm{w}}$ with TS, their interactions were studied. We noted that $\mathrm{pH}$ differentiated itself with the TS, as higher TS had slightly higher $\mathrm{pH}$ and the lower TS formulations had a $\mathrm{pH}$ value on the lower side. As expected, with increasing TS levels, we found a decreasing trend in $\mathrm{a}_{\mathrm{W}}$. These parameters were further studied for developing the interaction of the covariates using a mix plot, and 2 clusters, based on the $\mathrm{pH}$ and $\mathrm{a}_{\mathrm{w}}$, were observed (Figure 5). However, as the values within these 2 clusters were very close, and they did not play any important role in predicting the risk from Listeria. Hence, despite having slight variability in $\mathrm{pH}$ and $\mathrm{a}_{\mathrm{W}}$ and their interaction with TS levels, they did not appear to influence the overall

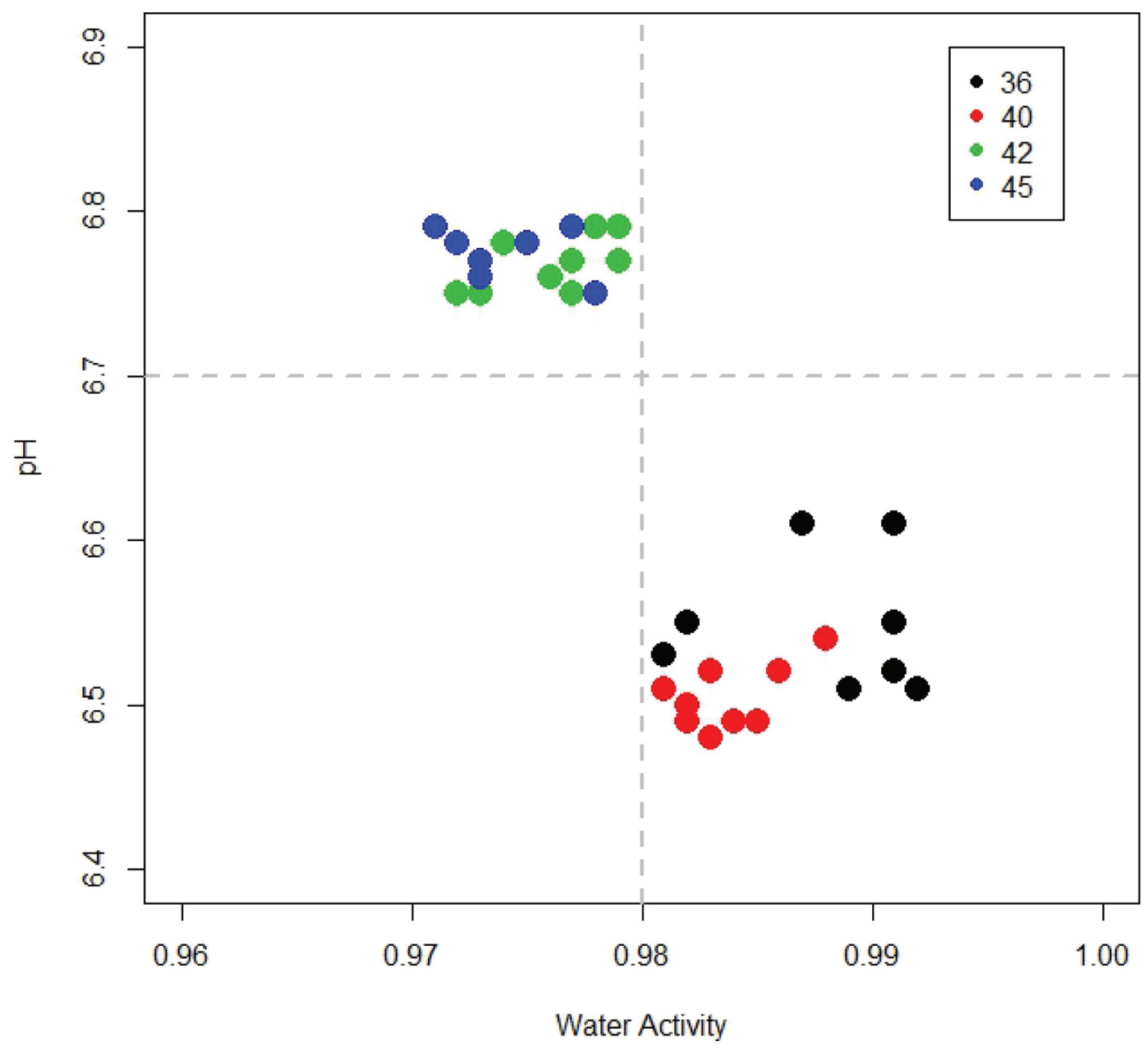

Figure 5. Scatterplot depicting clusters based on TS levels (36, 40, 42, and 45\%). Color version available online. 
occurrence of heat-injured cells, which was observed to be equal for all formulations. A previous report on ice cream mix components also concluded that the ice cream mix components showed no predictable influence on thermal stability of L. innocua (McKellar, 1996). These baselines values would be helpful in creating comparisons with temperature-abuse studies related to the interaction of covariates on the recovery potential of any heat-injured cells.

Industrial Application of Considering the Presence of Heat-Injured in Risk Analysis. The findings from our study can serve as a novel approach for Listeria risk assessment in the ice cream industry by considering the potential of the random presence of heat-injured cells using enrichment protocols. As both intrinsic as well as extrinsic factors related to ice cream manufacture are critical to comprehensively evaluate the risk from Listeria and to develop efficient risk assessment models, it would be justified to incorporate heat-injured cells and their recovery potential in developing these models. Furthermore, as ice cream manufacturing involves several processing stages, such as receiving raw ingredients, pasteurization, mix storage, freezing, hardening, and retailing, it is necessary to predict the fate of any cross contamination of Listeria at each processing stage. The present study showed the random presence of heat-injured cells through enrichment protocols only at the high level of cross contamination (log 4 or higher) when exposed to minimum pasteurization treatment. Under the conditions of experimentation, such heat-injured cells did not show any recovery during the normal storage of ice cream mix. However, the potential of injured cells to recover under any abused conditions cannot be ignored, and needs to be investigated further.

\section{CONCLUSIONS}

Many ice cream-related outbreaks have occurred in the recent past, mostly due to cross contamination under unhygienic processing conditions. Listeria is a very resilient organism that can withstand adverse conditions, such as wide ranges of $\mathrm{pH}$, water activity, and low temperatures. Its persistence in the dairy processing environment has been reported, as the organism can form resistant biofilms leading to potential cross contamination of the product, especially from harborage sites. Its ability to withstand adverse processing conditions may also lead to stressed and injured cells of Listeria, which may recover under abused conditions of handling and storage. Although such injured cells have not been linked to any disease outbreaks so far, this information could be helpful in improving risk assess- ment protocols. Keeping this in mind, the current study was conducted, focusing on the relationship of cross contamination levels at raw ice cream mix stage and the presence and recovery potential of heat-injured cells using enrichment protocols. When the raw ice cream mix samples were inoculated with about $\log 4.0 \mathrm{cfu} / \mathrm{g}$ of Listeria innocua (an established surrogate) and heat treated to minimum pasteurization treatment, the direct plating did not detect any survivors. On the other hand, BLEB enrichment protocol detected a random presence of heat-injured cells. Statistical algorithms were used to fit a model by considering covariates. Based on the quasicomplete separation, dose (level of cross contamination) came up as a predictor of the presence of heat-injured cells only at the higher levels of cross contamination (average log 4.0 or more). Further studies are necessary to evaluate the significance of the possibilities of random presence of heat-injured cells in ice cream mix when subjected to minimum pasteurization treatment. Importantly, ice cream mix itself did not support the recovery of any heat-injured cells during common aging and storage conditions $\left(7^{\circ} \mathrm{C}\right.$ for $72 \mathrm{~h}$ ), whereas the influence of any abused handling conditions is yet to be studied.

\section{ACKNOWLEDGMENTS}

This work was financially supported by Midwest Dairy Foods Research Center. The authors also acknowledge the support of the Agricultural Experimentation Station, South Dakota State University, in conducting this study, and the Electrical Engineering Department, South Dakota State University, for helping with scanning electron microscope work.

\section{REFERENCES}

Alessandria, V., K. Rantsiou, P. Dolci, and L. Cocolin. 2010. Molecular methods to assess Listeria monocytogenes route of contamination in a dairy processing plant. Int. J. Food Microbiol. 141:S156-S162.

Bearns, R. E., and K. F. Girard. 1958. The effect of pasteurization on Listeria monocytogenes. Can. J. Microbiol. 4:55-61.

Besse, N. 2002. Influence of various environmental parameters and of detection procedures on the recovery of stressed L. monocytogenes: A review. Food Microbiol. 19:221-234.

Bradshaw, J. G., J. T. Peeler, J. J. Corwin, J. M. Hunt, and R. M. Twedt. 1987. Thermal resistance of Listeria monocytogenes in Dairy Products. J. Food Prot. 50:543-544.

Buchanan, R. L. 1990. Advances in culture methods for detection of Listeria monocytogenes. Pages 85-95 in Foodborne Illness. A. J. Miller, J. L. Smith, and S. A. Somkuti, ed. Society for Industrial Microbiology, Washington, DC.

Bunduki, M. M.-C., K. J. Flanders, and C. W. Donnelly. 1995. Metabolic and structural sites of damage in heat- and sanitizer-injured populations of Listeria monocytogenes. J. Food Prot. 58:410-415.

Bunning, V. K., C. W. Donnelly, J. T. Peeler, E. H. Briggs, J. G. Bradshaw, R. G. Crawford, C. M. Beliveau, and J. T. Tierney. 1988. Thermal inactivation of Listeria monocytogenes within bovine milk phagocytes. Appl. Environ. Microbiol. 54:364-370. 
Campbell, M. 2015. An examination of microbial populations in different brands and flavors of Ice cream. Undergraduate thesis, Dept. of Biology, University of Mississippi, Oxford.

Centers for Disease Control and Prevention (CDC). 2015. Multistate Outbreak of Listeriosis Linked to Blue Bell Creameries Products. Accessed Aug. 15, 2018. https://www.cdc.gov/listeria/outbreaks/ ice-cream-03-15/index.html.

Chen, Y., E. Allard, A. Wooten, M. Hur, I. Sheth, A. Laasri, T. S Hammack, and D. Macarisin. 2016. Recovery and growth potential of Listeria monocytogenes in temperature abused milkshakes prepared from naturally contaminated ice cream linked to a listeriosis outbreak. Front. Microbiol. 7:764

Choi, K. H., H. Lee, S. Lee, S. Kim, and Y. Yoon. 2016. Cheese microbial risk assessments - A Review. Asian-Australas. J. Anim. Sci. $29: 307-314$.

Codex Alimentarius Commission. 1999. Principles and Guidelines for the Conduct of Microbiological Risk Assessment. (CAC/GL 30 - 1999): 1-15. International Food Standards, FAO of the United Nations and World Health Organization, Rome, Italy.

Doyle, M. P., K. A. Glass, J. T. Beery, G. A. Garcia, D. J. Pollard, and R. D. Schultz. 1987. Survival of Listeria monocytogenes in milk during high-temperature, short-time pasteurization. Appl. Environ. Microbiol. 53:1433-1438.

Environmental Protection Agency. 2012. Microbial risk assessment guideline: Pathogenic microorganisms with focus on food and water. U.S. Environmental Protection Agency; U.S. Department of Agriculture, Food Safety and Inspection Service, Washington, DC.

Farber, J., E. Dailey, D. B. Emmons, and R. Mckellar. 1992. Factor influencing survival of Listeria monocytogenes in milk in a hightemperature short-time pasteurizer. J. Food Prot. 55:946-951.

Farber, J. M., and P. Peterkin. 1991. Listeria monocytogenes, a foodborne pathogen. Microbiol. Rev. 55:476-511.

Farber, J. M., G. Sanders, J. Speirs, J.-Y. Daoust, D. Emmons, and R. Mckellar. 1988. Thermal resistance of Listeria monocytogenes in inoculated and naturally contaminated raw milk. Int. J. Food Microbiol. 7:277-286.

Fernandez Garayzabal, J. F., L. D. Rodriguez, J. A. V. Boland, E. F. R. Ferri, V. B. Dieste, J. L. B. Cancelo, and G. S. Fernandez. 1987. Survival of Listeria monocytogenes in raw milk treated in a pilot plant size pasteurizer. J. Appl. Bacteriol. 63:533-537.

Flanders, K. J., T. J. Pritchard, and C. W. Donnelly. 1994. Enhances recovery of Listeria from dairy-plant processing environments through combined use of repair enrichment and selective enrichment/detection procedures. J. Food Prot. 58:404-409.

Fleming, D. W., S. L. Cochi, K. L. MacDonald, J. Brondum, S. P. S. Hayes, B. D. Pllikaytis, M. B. Holmes, A. Audurier, C. V. Broome, and A. L. Reingold. 1985. Pasteurized milk as a vehicle of infection in an outbreak of Listeriosis. N. Engl. J. Med. 312:404-407.

Food and Drug Administration (FDA). 2018. Fieldbrook Foods Corporation, announces an extension of voluntary recall of orange ice cream bars and chocolate coated vanilla ice cream bars for possible health risk. Accessed Apr. 12, 2018. https://www.fda.gov/Safety/ Recalls/ucm591923.htm.

FDA. 2015. Pasteurized milk ordinance. US Department of Health and Human Services, Public Health Service, Food and Drug Administration, Silver Spring, MD.

FDA. 2016. Jeni's Splendid Ice Creams, LLC 8/9/16. Accessed Aug. 15, 2018. https://www.fda.gov/iceci/enforcementactions/ warningletters/2016/ucm516395.htm.

FDA. 2017. Detection of Listeria monocytogenes in foods and environmental samples, and enumeration of listeria monocytogenes in foods. Chapter 10 in Bacteriological Analytical Manual (BAM). Accessed Aug. 15, 2018. https://www.fda.gov/food/ foodscienceresearch/laboratorymethods/ucm071400.htm.

Fox, E., T. Omahony, M. Clancy, R. Dempsey, M. Obrien, and K. Jordan. 2009. Listeria monocytogenes in the Irish dairy farm environment. J. Food Prot. 72:1450-1456.

Friedly, E. C., P. G. Crandall, S. Ricke, C. A. O'Bryan, E. M. Martin, and L. M. Boyd. 2008. Identification of Listeria innocua surro- gates for Listeria monocytogenes in hamburger patties. J. Food Sci. 73:M174-M178.

FSIS. 2014. Compliance guideline: Controlling Listeria monocytogenes in post-lethality exposed ready-to -eat meat and poultry products. Accessed Aug. 15, 2018. https://www.fsis.usda.gov/wps/wcm/ connect/d3373299-50e6-47d6-a577-e74a1e549fde/Controlling-Lm -RTE-Guideline.pdf?MOD=AJPERES.

Glicksman, M. 1983. Red seaweed extracts (agar, carrageenans, furcellaran). Pages 73-113 in Food Hydrocolloids, vol II. M. Glicksman, ed. CRC Press, Boca Raton, FL.

Gougouli, M., A. Angelidis, and K. Koutsoumanis. 2008. A study on the kinetic behavior of Listeria monocytogenes in ice cream stored under static and dynamic chilling and freezing conditions. J. Dairy Sci. 91:523-530.

Hansen, T. B., and S. Knøchel. 2001. Factors influencing resuscitation and growth of heat injured Listeria monocytogenes in sous vide cooked beef. Int. J. Food Microbiol. 63:135-147.

Hassan, A. N., S. Anand, and M. Avadhanula. 2010. Microscopic observation of multispecies biofilm of various structures on whey concentration membranes. J. Dairy Sci. 93:2321-2329.

Hauben, K. J. A., E. Y. Wuytack, C. C. F. Soontjens, and C. W. Michiels. 1996. High-pressure transient sensitization of Escherichia coli to lysozyme and nisin by disruption of outer-membrane permeability. J. Food Prot. 59:350-355.

Holsinger, V. H., P. W. Smith, J. L. Smith, and S. A. Palumbo. 1992 Thermal destruction of Listeria monocytogenes in ice cream mix. J. Food Prot. 55:234-237.

Hunt, K., N. Drummond, M. Murphy, F. Butler, J. Buckley, and K. Jordan. 2012. A case of bovine raw milk contamination with Listeria monocytogenes. Ir. Vet. J. 65:13.

Jasson, V., L. Jacxsens, P. Luning, A. Rajkovic, and M. Uyttendaele. 2010. Alternative microbial methods: An overview and selection criteria. Food Microbiol. 27:710-730.

Knabel, S. J., H. W. Walker, P. A. Hartman, and A. F. Mendonca. 1990. Effects of growth temperature and strictly anaerobic recovery of on the survival of Listeria monocytogenes during pasteurization. Appl. Environ. Microbiol. 56:370-376.

Liu, S., V. M. Puri, and A. Demirci. 2009. Evaluation of Listeria innocua as a suitable indicator for replacing Listeria monocytogenes during ripening of Camembert cheese. Int. J. Food Sci. Technol. 44:29-35.

Lou, Y., and A. E. Yousef. 1999. Characteristics of Listeria monocytogenes important to food processors. Pages 131-225 in Listeria Listeriosis, and Food Safety. 2nd ed. E. T. Ryser, and E. H. Marth, ed. Marcel Dekker, New York, NY.

Lund, A. M., E. A. Zottola, and D. J. Pusch. 1991. Comparison of methods for isolation of Listeria from raw milk. J. Food Prot. 54:602-606.

Mackey, B. M., E. Boogard, C. Hayes, and J. Baranyi. 1994. Recovery of heat-injured Listeria monocytogenes. Int. J. Food Microbiol. $22: 227-237$

McKellar, R. 1996. Influence of ice-cream mix components on the thermal stability of bovine milk $\gamma$-glutamyl transpeptidase and Listeria innocua. Int. Dairy J. 6:1181-1189.

McMahon, C. M., C. Byrne, J. Sheridan, D. Mcdowell, I. Blair, and T. Hegarty. 2000. The effect of culture growth phase on induction of the heat shock response in Yersinia enterocolitica and Listeria monocytogenes. J. Appl. Microbiol. 89:198-206.

Nightingale, K. K., Y. H. Schukken, C. R. Nightingle, E. D. Fortes, A. J. Ho, Z. Her, Y. T. Grohn, P. L. Mcdonough, and M. Weidmann. 2004. Ecology and transmission of Listeria monocytogenes infecting ruminants and in the farm Environment. Appl. Environ. Microbiol. 70:4458-4467.

Niven, G. W., C. A. Miles, and B. M. Mackey. 1999. The effects of hydrostatic pressure on ribosome conformation in Escherichia coli: An in vivo study using differential scanning calorimetry. Microbiology 145:419-425.

Novak, J. S., and V. K. Juneja. 2001. Detection of heat injury in Listeria monocytogenes Scott A. J. Food Prot. 64:1739-1743. 
O'Donnell, E. T. 1995. The incidence of Salmonella and Listeria in raw milk from farm bulk tanks in England and Wales. Int. J. Dairy Technol. 48:25-29.

Pagán, R., and B. Mackey. 2000. Relationship between membrane damage and cell death in pressure-treated Escherichia coli cells: Differences between exponential and stationary phase cells and variation among strains. Appl. Environ. Microbiol. 66:2829-2834.

Park, S.-H., P.-S. Chang, S. Ryu, and D.-H. Kang. 2014. Development of a novel selective and differential medium for the isolation of Listeria monocytogenes. Appl. Environ. Microbiol. 80:1020-1025.

Pascual, C., T. P. Robinson, M. J. Ocio, O. O. Aboada, and B. M. Mackey. 2001. The effect of inoculum size and sublethal injury on the ability of Listeria monocytogenes to initiate growth under suboptimal conditions. Lett. Appl. Microbiol. 33:357-361.

Pritchard, T. J., and C. W. Donnelly. 1999. Combined secondary enrichment of primary enrichment broths increase Listeria detection. J. Food Prot. 62:532-535.

Ritz, M., J. Tholozan, M. Federighi, and M. Pilet. 2002. Physiological damages of Listeria monocytogenes treated by high hydrostatic pressure. Int. J. Food Microbiol. 79:47-53.

Ritz, M., J. L. Tholozan, M. Federighi, and M. F. Pilet. 2001. Morphological and physiological characterization of Listeria monocytogenes subjected to high hydrostatic pressure. Appl. Environ. Microbiol. 67:2240-2247.

Roso, L. 1995. Modeling and predictive microbiology; Development of a new tool for the food industry. PhD Thesis. University Claude Bernard, Lyon, France.
Sanaa, M., B. Poutrel, J. Menard, and F. Serieys. 1993. Risk factors associated with contamination of raw milk by Listeria monocytogenes in dairy farms. J. Dairy Sci. 76:2891-2898.

Tharrington, G., and K. M. Sorrells. 1992. Inhibition of Listeria monocytogenes by milk culture filtrates from Lactobacillus delbruecki ssp. lactis. J. Food Prot. 55:542-544.

Thouvenot, P., G. Vales, H. Bracq-Dieye, N. Tessaud-Rita, M. M. Maury, A. Moura, M. Lecuit, and A. Leclercq. 2018. MALDI-TOF mass spectrometry-based identification of Listeria species in surveillance: A prospective study. J. Microbiol. Methods 144:29-32.

Vlaemynck. G. M., and R. Moermans. 1996. Comparison of EB and Fraser enrichment broths for the detection of Listeria spp. and Listeria monocytogenes in raw milk dairy products and environmental samples. J. Food Prot. 59:1172-1175.

Warburton, D. W., J. M. Farber, A. Armstrong, R. Calderia, T. Hunt, S. Messier, R. Plante, N. P. Tiwari, and J. Vinet. 1991. A comparison study of the "FDA" and the "USDA" methods for the detection of Listeria monocytogenes in foods. Int. J. Food Microbiol. 13:105-117.

Wehr, H. M., and J. F. Frank. 2004. Standard Methods for the Examination of Dairy Products. 17th ed. American Public Health Association, Washington, DC. 